\title{
Factors associated with the attitudes of oncology nurses toward hospice care in China
}

\author{
This article was published in the following Dove Press journal: \\ Patient Preference and Adherence \\ 5 May 2017 \\ Number of times this article has been viewed
}

\author{
Fei-Min Yang' \\ Zhi-Hong Ye ${ }^{2}$ \\ Lei-Wen Tang ${ }^{3}$ \\ Wei-Lan Xiang ${ }^{3}$ \\ Lin-Juan Yan ${ }^{4}$ \\ Min-Li Xiang ${ }^{5}$ \\ 'Department of General Surgery, \\ ${ }^{2}$ Department of Nursing, ${ }^{3}$ Department \\ of Nursing Education, ${ }^{4}$ Department \\ of Surgical Oncology, ${ }^{5}$ Department of \\ Medical Oncology, Sir Run Run Shaw \\ Hospital, School of Medicine, Zhejiang \\ University, Hangzhou, China
}

Objective: To examine factors that are associated with the apprehension levels of oncology nurses toward hospice care. Factors examined in this study included demographics, nursing experience, education levels, title and post, personal experiences, and attitudes toward endof-life care.

Methods: Questionnaires were provided to nurses $(n=201)$ from three first-tier hospitals in China. A quantitative scale, Professional End-of-life Care Attitude Scale (PEAS), was used to assess personal and professional apprehension levels toward hospice care. The PEAS was translated to Chinese with terms adapted to the cultural environment in China. Statistical analyses were performed to examine the relationships between the apprehension levels and various factors.

Results: The total PEAS scores exhibited internal consistency and reliability, with a Cronbach $\alpha=0.897$ and Pearson's $r=0.9030$. Of the 201 nurses, 184 provided a valid response $(91.5 \%)$. Education level was significantly correlated with personal $(P<0.01)$ and professional apprehension levels $(P<0.05)$. Higher apprehension level was found in nurses with less education.

Conclusion: The PEAS quantitative survey is useful for evaluating apprehension levels of nurses toward hospice care. Nurses with more education experienced less anxiety when providing care for terminally ill patients. The findings suggested that education programs on hospice care could be strengthened to help nurses cope with negative attitudes toward end-of-life care.

Keywords: end of life, nurses' perspective, communication, palliative care, cancer patients, terminally ill

\section{Introduction}

Hospice care, as an emerging discipline in modern nursing, is specialized care that provides medical, psychological, and spiritual support to dying patients and their family members. ${ }^{1}$ Instead of curing disease or prolonging life, hospice care focuses on pain and symptom control to enable patients to spend their last days of life with good quality. Hospice care is most appropriate when a terminally ill patient no longer benefits from curative treatments, and his or her estimated survival is $<6$ months. This condition is not uncommon for patients with advanced cancer. In China, the cases of cancer and cancer-related deaths have been increasing, making cancer the leading cause of death. It is estimated that $\sim 4.3$ million new cancer cases and 2.8 million cancer deaths will occur in China per year. ${ }^{2}$ Much of the medical support and hospice care are needed for these patients.

Patients usually spend their last days of life in hospitals, and nurses are frequently exposed to deaths in the course of their clinical work. Nursing care for terminally ill patients is emotionally demanding work. It has been reported that end-of-life care is one of the most common sources of stress for nurses. ${ }^{3}$ Not only the nurses need to deal with patients but also with patients' grieving families. The discussion on death
Department of Nursing, Sir Run Run Shaw Hospital, School of Medicine, Zhejiang University, No 3 East Qingchun Road, Hangzhou 310016 , China

Tel +86 57I 86006608

Fax +8657186006616

Email yezl@srrsh.com 
and dying issues is burdensome. ${ }^{4}$ A study reported that $\sim 91 \%$ of nurses were unsure how to react when patients talked about death and dying. ${ }^{4}$ Some nurses may choose to avoid discussing the emotional issues with patients, and some may choose not to tell the truth about the patient's condition. ${ }^{4,5}$ The differences in reactions may be attributed to factors such as personal attitudes to death, experiences, understanding on end-of-life care, and so on. The factors will finally shape the care that is provided whether the nurses are aware of it or not.

The understanding of the factors that affect the attitudes of nurses will help to develop strategies and resources they need to use to cope in stressful situations. Quantitative studies exploring nurses' death anxiety and attitudes toward hospice care were reported. ${ }^{6-9}$ However, such studies are limited in China. This study explored the level of apprehension of oncology nurses from three hospitals and investigated factors that affect the apprehension level.

\section{Patients and methods Participants}

This study was approved by the ethics committees of the three hospitals (Zhejiang Provincial Hospital of TCM; Sir Run Run Shaw Hospital, School of Medicine, Zhejiang University; and Zhejiang Cancer Hospital) in this study, and signed informed consent was obtained from participants regarding the use of questionnaire results for research. A total of 201 nurses agreed to participate in this study. They were working in the Oncology Department of the three 3A hospitals in Zhejiang Province, China. The hospitals in China are designated according to a three-tier system that recognizes a hospital's ability to provide medical care, medical education, and conduct medical research. A ' $3 \mathrm{~A}$ ' hospital is recognized as one that has the highest degree of care. The three $3 \mathrm{~A}$ hospitals are of different specialties, namely a Western medicine-orientated general hospital, a Chinese traditional medicine-orientated general hospital, and a tumor hospital.

Questionnaires were given to the 201 nurses in the period of October 2011 to March 2012, and 184 valid responses $(91.5 \%)$ were received. Responses with fixed answers or with $>10 \%$ unanswered questions were excluded from analyses. For a question with a missing value, the average score of the question was used. The study cohort included 183 females $(99.5 \%)$ and one male $(0.5 \%)$. The age ranged from 21 to 45 years old, of which 119 subjects (64.7\%) were from 21 to 30 years old. Other background information of the nurses is summarized in Table S1.

\section{Questionnaires}

The survey used a Chinese version of the Professional Endof-life Care Attitude Scale (PEAS) established by Levetown et al in $1999 .{ }^{10}$ The PEAS was translated to Chinese by a Master's holder with nursing as major, and then revised by two oncologists who hold doctoral degrees. The Chinese version of PEAS used in this study showed a validity of 0.903 , a test-retest reliability of 0.913 , and an internal consistency coefficient of 0.897 .

The survey included four parts: 1) instructions for completing the survey, 2) collection of background information of the subjects, 3 ) questions on training/personal experiences on hospice care (Table S2; PEAS tools, Part A Questions), and 4) knowledge/attitudes toward hospice care (Table S2; PEAS tools, Part B Questions).

In Part 3, there were a total of nine questions on the training/personal experiences of hospice care, and the answers were scored as -1 (false), 0 (not applicable), and 1 (true). Therefore, the highest score attainable in this part was 9 .

In Part 4, there were 31 questions. These questions on the knowledge/attitudes toward hospice care could be subdivided into two components: A) personal apprehension level (13 questions), and B) professional apprehension level (18 questions). The 13 questions on personal apprehensive level described personal feelings as an individual about interacting with dying patients and their families (eg, feeling angry or guilty when patients die). The other 18 questions on professional apprehension level assessed the responses, as a professional role, in certain situations (eg, remaining unemotional in caring for dying patient or withholding information from the patient). The responses were scored from 0 to 5, representing "not applicable," "strongly disagreed," "disagreed," "neutral," "agreed," and "strongly agreed," respectively. Therefore, the highest score attainable in this part was 155 (65 from personal and 90 from professional apprehension level).

Researchers explained to the participants the content of the questionnaire and the ways to complete the questions. Subjects were required to complete the questionnaire anonymously and independently. Completed questionnaires were returned to the researchers.

\section{Statistical analysis}

The data were analyzed using SPSS 16.0. $P<0.05$ was defined as statistically significant. Chi-squared test, $t$-test, and Mann-Whitney $U$-test were used to analyze differences between groups. Correlation analyses were performed using Spearman's rank test. 


\section{Results}

The results on the section of formal training/personal experiences on hospice care showed that the majority of nurses $(80.4 \%)$ received courses on hospice care in school, and $44.6 \%$ nurses received practical training during internship. In terms of personal experiences, $59.2 \%$ had visited dying patients in hospital and $16.8 \%$ had visited dying patients at home. The results indicated that most of the nurses were exposed to the process of hospice care through course work, and not many of them had their own experiences on the processes accompanying death. Despite $84.2 \%$ of nurses who had autonomy and rights to make life choices, only $14.7 \%$ of nurses had estate planning, indicating a certain degree of avoidance on the reality of deaths.

Next, the authors investigated the factors associated with overall attitude toward hospice care (total score of personal and professional apprehension level) and training/ personal experiences. The correlation analyses showed that age was associated with personal apprehension level $(P<0.05)$. Education level was significantly correlated with personal $(P<0.01)$ and professional apprehension levels $(P<0.05)$, as well as the overall attitude $(P<0.01)$ (Table 1). In addition, the variance analysis showed that nurses with different education levels had significantly different scores $(P<0.05)$ on personal apprehension and overall attitude toward hospice care; the higher the education level attained, the lower the personal and profession apprehension levels (Table 2).

Further analyses on other parameters showed that working experiences affected professional level. Nurses with 11-15 years of experience had the lowest professional apprehension score, while those with $\geq 21$ years of experiences had the highest apprehension score (Table 3$)$. In addition to working experiences, both post $(P=0.047)$ and title $(P=0.047)$ of nurses were related to the professional apprehension levels (Tables 4 and 5). Nurses with a post of managers or above had the highest professional apprehension level (57.08 \pm 4.66$)$, and nurses with a title of co-chief nurse or above had the highest professional apprehension

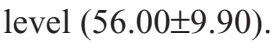

Finally, the authors found that age was significantly associated with personal $(P=0.027)$ and professional apprehension level $(P=0.016)$ (Table 6). The association with the overall attitude was barely significant $(P=0.058)$. Nurses in the youngest age group (21-25 years old) had the highest score on personal apprehension level (41.79 \pm 6.18$)$. Nurses in the older age group (41 years or older) had the highest score on professional apprehension level (59.75 \pm 5.12$)$.

\section{Discussion}

The Chinese version of PEAS was established in this study, with satisfactory validity and reliability to assess the attitude of oncology nurses toward hospice care. The scale used in this study is a brief version of PEAS. It has been widely used in the US to evaluate the uncomfortable emotions and attitudes of clinical nurses providing care to patients at the terminal stages of life. However, similar studies in China are limited. Perhaps one of the reasons was that the terms used in the original version of the attitude scale are not suitable to be used in Asian countries, due to differences in culture, religion, health care system, etc. This study developed a Chinese version of PEAS, with the terms adapted to the Chinese culture. This version of PEAS could be useful for future research in this area in China.

This study showed that most of the oncology nurses (84\%) from 3A hospitals received course work on hospice care in their training, but not many of them had experiences in processes involving patient deaths at both personal and professional levels. Nursing practice in the area of hospice care is important. The future design of the curriculum may include more practical training or experiential learning on hospice care, such as hospice visits, ${ }^{11}$ and intensive education programs focusing on death, and dying.

The authors investigated the association of factors, including age, sex, marital status, religion, working experience, education level, working department, post, and titles with the attitudes toward hospice care. The education levels were negatively correlated with the personal attitude, professional attitude, and overall hospice care attitude (ie, the higher the education level, the lower the apprehension level), indicating death education is important to reduce death anxiety. ${ }^{12,13}$ The future curriculum on hospice care may also include research topics to allow nurses to have deeper understanding on end-of-life care. Some research topics are especially relevant to help establishing end-of-life care in China, including the implementation of three-step therapy of using pain medication, ${ }^{14,15}$ and establishment of standard hospice care protocol.

In addition to education level, the authors also found that years of nursing experience was associated with the professional apprehension level. The decrease in apprehensive level was observed with increase in nursing experience in the three groups: $21-25,26-30$, and $31-35$ years. This is in accordance with the findings that those with more experience had more positive attitudes toward death. ${ }^{6,7,9}$ However, in this study the apprehension level increased again in the groups of 36-40 years and $\geq 41$ years. This might be due 
Table I Correlation between demographic variables and apprehension levels of hospice care $(n=184)$

\begin{tabular}{lllll}
\hline & $\begin{array}{l}\text { Personal } \\
\text { apprehension level }\end{array}$ & $\begin{array}{l}\text { Professional } \\
\text { apprehension level }\end{array}$ & Overall attitude & $\begin{array}{l}\text { Training/personal } \\
\text { experiences }\end{array}$ \\
\hline Age & $-\mathbf{0 . 1 5 9 *}$ & 0.114 & 0.006 & 0.122 \\
Sex & -0.057 & -0.045 & -0.063 & 0.113 \\
Marital status & 0.085 & 0.016 & 0.060 & -0.052 \\
Religion & 0.004 & -0.047 & -0.029 & 0.047 \\
Working experiences & -0.047 & 0.081 & 0.049 & 0.056 \\
Department & 0.054 & -0.041 & -0.015 & 0.053 \\
Education level & $-\mathbf{0 . 2 7 3 * *}$ & $-0.163^{*}$ & $-\mathbf{0 . 2 4 4 *}$ & 0.054 \\
Rankings & -0.124 & -0.021 & -0.063 & 0.031 \\
\hline
\end{tabular}

Notes: Data in bold indicates statistical significance. $* P<0.05 ; * * P<0.0$ I.

Table 2 Variance analysis on the apprehension levels in groups with different education level (mean \pm standard deviation) ( $\mathrm{n}=184)$

\begin{tabular}{lllllll}
\hline & $\begin{array}{l}\text { Technical secondary } \\
\text { school graduates }\end{array}$ & $\begin{array}{l}\text { Junior college } \\
\text { graduates }\end{array}$ & Bachelor's & $\begin{array}{l}\text { Master's } \\
\text { or above }\end{array}$ & $\boldsymbol{F}$ & $\boldsymbol{P}$-value \\
\hline Personal apprehension level & $46.60 \pm 17.53$ & $42.00 \pm 6.80$ & $38.96 \pm 5.29$ & $37.00 \pm 2.83$ & 4.970 & $\mathbf{0 . 0 0 2} * *$ \\
Profession apprehension level & $57.60 \pm 7.20$ & $53.93 \pm 7.37$ & $51.58 \pm 7.18$ & $53.50 \pm 3.87$ & 2.145 & 0.096 \\
Overall attitude & $105.50 \pm 13.62$ & $95.21 \pm 1.75$ & $90.52 \pm 0.88$ & $90.50 \pm 2.60$ & 4.201 & $\mathbf{0 . 0 0 7 * *}$ \\
\hline
\end{tabular}

Notes: Data in bold indicates statistical significance. $* * P<0.01$.

Table 3 Variance analysis on the apprehension levels in groups with different nursing experience (mean \pm standard deviation) ( $\mathrm{n}=184)$

\begin{tabular}{|c|c|c|c|c|c|c|c|}
\hline & $\leq 5$ years & $6-10$ years & $11-15$ years & $16-20$ years & $\geq 21$ years & $\boldsymbol{F}$ & $P$-value \\
\hline Personal apprehension level & $40.68 \pm 6.12$ & $39.22 \pm 5.37$ & $38.7 I \pm 6.30$ & $39.90 \pm 3.94$ & $4|.43 \pm| 6.5 \mid$ & 0.806 & 0.523 \\
\hline Professional apprehension level & $52.74 \pm 6.58$ & $51.37 \pm 7.85$ & $50.74 \pm 8.69$ & $53.43 \pm 3.01$ & $60.14 \pm 6.69$ & 2.985 & $0.021 *$ \\
\hline Overall attitude & $92.87 \pm 1.23$ & $90.50 \pm 1.63$ & $89.48 \pm 2.07$ & $93.33 \pm 0.96$ & $101.57 \pm 8.07$ & 2.219 & 0.069 \\
\hline
\end{tabular}

Notes: Data in bold indicates statistical significance. $* P<0.05$.

Table 4 Variance analysis on the apprehension levels in nurses with different posts (mean \pm standard deviation) ( $\mathrm{n}=184)$

\begin{tabular}{llllll}
\hline & Clinical nurse & Group leader & $\begin{array}{l}\text { Managers of head } \\
\text { nurse and above }\end{array}$ & F & P-value \\
\hline Personal apprehension level & $40.09 \pm 5.79$ & $39.80 \pm 8.75$ & $37.77 \pm 4.80$ & 0.783 & 0.459 \\
Professional apprehension level & $52.17 \pm 6.76$ & $51.37 \pm 9.19$ & $57.08 \pm 4.66$ & 3.198 & $\mathbf{0 . 0 4 3 *}$ \\
Total scale & $92.05 \pm 0.87$ & $90.88 \pm 2.76$ & $94.85 \pm 1.64$ & 0.603 & 0.548 \\
\hline
\end{tabular}

Notes: Data in bold indicates statistical significance. $* P<0.05$.

Table 5 Variance analysis on the apprehension levels in nurses with different titles (mean \pm standard deviation) $(n=184)$

\begin{tabular}{|c|c|c|c|c|c|c|}
\hline & Nurse & Senior nurse & Supervisor nurse & $\begin{array}{l}\text { Co-chief nurse } \\
\text { and above }\end{array}$ & $F$ & $P$-value \\
\hline Personal apprehension level & $41.13 \pm 6.77$ & $39.57 \pm 5.34$ & $39.34 \pm 8.22$ & $34.00 \pm 7.07$ & 1.343 & 0.262 \\
\hline Professional apprehension level & $54.06 \pm 6.71$ & $50.99 \pm 7.16$ & $53.7 I \pm 7.60$ & $56.00 \pm 9.90$ & 2.709 & $0.047 *$ \\
\hline Total scale & $94.57 \pm|.7|$ & $90.4 I \pm 0.98$ & $93.2 \mathrm{I} \pm 2.34$ & $90.00 \pm 2.00$ & 1.668 & 0.176 \\
\hline
\end{tabular}

Notes: Data in bold indicates statistical significance. $* P<0.05$.

Table 6 Variance analysis on the apprehension levels in nurses of different age groups (mean \pm standard deviation) ( $\mathrm{n}=184)$

\begin{tabular}{|c|c|c|c|c|c|c|c|}
\hline & $2 \mathrm{I}-25$ years old & $26-30$ years old & $3 I-35$ years old & $36-40$ years old & $\geq 41$ years old & $\boldsymbol{F}$ & $P$-value \\
\hline Personal apprehension level & $41.79 \pm 6.18$ & $39.27 \pm 5.84$ & $38.08 \pm 4.93$ & $40.62 \pm 9.22$ & $35.75 \pm 7.27$ & 2.808 & $0.027 *$ \\
\hline Professional apprehension level & $52.93 \pm 6.82$ & $50.74 \pm 7.55$ & $51.68 \pm 7.86$ & $55.52 \pm 4.62$ & $59.75 \pm 5.12$ & 3.126 & $0.016 *$ \\
\hline Total scale & $94.07 \pm 1.43$ & $90.02 \pm 1.44$ & $89.61 \pm 1.65$ & $96.14 \pm 2.67$ & $95.50 \pm 5.20$ & 2.328 & 0.058 \\
\hline
\end{tabular}

Notes: Data in bold indicates statistical significance. $* P<0.05$. 
to the lack of hospice care education in China during early years. Nurses with working experience of $\geq 36$ years mostly graduated from a technical secondary school, where hospice care education is generally not available. This finding is unique and it would be worthwhile to have additional subjects from this age group ( $>36$ years old) to further assess the roles of working experience and hospice education in apprehension level.

There are limitations to this study. First, it is a descriptive study that provides associations of certain parameters with personal/professional apprehensive levels, which does not necessarily translate to causal relationship. Additional subjects and assessments will be needed to power the study for a conclusive outcome on causal relationship. Future study with a longitudinal follow-up of nurses will also provide important understanding of the factors that affect apprehensive levels.

In conclusion, the authors have developed the Chinese version of PEAS that could be used to assess the knowledge and attitude of oncology nurses toward hospice care. It is recommended to strengthen the practical training on hospice care to prepare nurses for the emotionally demanding work.

\section{Disclosure}

The authors report no conflicts of interest in this work.

\section{References}

1. D'Antonio J. End-of-life nursing care and education: end-of-life nursing education: past and present. J Christ Nurs. 2017;34(1):34-38.

2. Chen W, Zheng R, Baade DP, et al. Cancer statistics in China, 2015. CA Cancer J Clin. 2016;66(2):115-132.
3. Gibbons C, Dempster M, Moutray M. Stress, coping and satisfaction in nursing students. $J$ Adv Nurs. 2011;67(3):621-632.

4. Sasahara T, Miyashita M, Kawa M, Kazuma K. Difficulties encountered by nurses in the care of terminally ill cancer patients in general hospitals in Japan. Palliat Med. 2003;17(6):520-526.

5. Iranmanesh S, Dargahi H, Abbaszadeh A. Attitudes of Iranian nurses toward caring for dying patients. Palliat Support Care. 2008;6(4): 363-369.

6. Deffner JM, Bell SK. Nurses' death anxiety, comfort level during communication with patients and families regarding death, and exposure to communication education: a quantitative study. J Nurses Staff Dev. 2005;21(1):19-23; quiz 24-25.

7. Zyga S, Malliarou M, Lavdaniti M, Athanasopoulou M, Sarafis P. Greek renal nurses' attitudes towards death. J Ren Care. 2011;37(2): 101-107.

8. Braun M, Gordon D, Uziely B. Associations between oncology nurses' attitudes toward death and caring for dying patients. Oncol Nurs Forum. 2010;37(1):E43-E49.

9. Lange M, Thom B, Kline NE. Assessing nurses' attitudes toward death and caring for dying patients in a comprehensive cancer center. Oncol Nurs Forum. 2008;35(6):955-959.

10. Levetown M, Hayslip B, Peel J. The development of the physicians' endof-life care attitude scale. Omega (Westport). 1999;40(2):323-333.

11. Kwekkeboom KL, Vahl C, Eland J. Companionship and education: a nursing student experience in palliative care. J Nurs Educ. 2005;44(4): $169-176$.

12. Gillan PC, van der Riet PJ, Jeong S. End of life care education, past and present: a review of the literature. Nurse Educ Today. 2014;34(3): $331-342$.

13. Jafari M, Rafiei H, Nassehi A, SoleimaniF, Arab M, Noormohammadi MR. Caring for dying patients: attitude of nursing students and effects of education. Indian J Palliat Care. 2015;21(2):192-197.

14. Randall-David E, Wright J, Porterfield DS, Lesser G. Barriers to cancer pain management: home-health and hospice nurses and patients. Support Care Cancer. 2003;11(10):660-665.

15. Oxenham D, Duncan R, Fischbacher M. Cancer pain management in Lanarkshire: a community-based audit. Palliat Med. 2003;17(8): 708-713. 


\section{Supplementary materials}

Table SI Background information of the 184 nurses who participated in the study

\begin{tabular}{|c|c|}
\hline Background information & Frequency, n (\%) \\
\hline \multicolumn{2}{|l|}{ Hospitals } \\
\hline A: Western medicine-orientated & $72(39.1)$ \\
\hline B: Chinese traditional medicine-orientated & $48(26.7)$ \\
\hline C: tumor hospital & $64(34.2)$ \\
\hline \multicolumn{2}{|l|}{ Age (years) } \\
\hline $21-25$ & $57(31.0)$ \\
\hline $26-30$ & $62(33.7)$ \\
\hline $3 \mathrm{I}-35$ & $40(21.7)$ \\
\hline $36-40$ & $21(1 I .4)$ \\
\hline$\geq 41$ & $4(2.2)$ \\
\hline \multicolumn{2}{|l|}{ Sex } \\
\hline Male & $\mathrm{I}(0.5)$ \\
\hline Female & $183(99.5)$ \\
\hline \multicolumn{2}{|l|}{ Marital status } \\
\hline Married & $104(56.5)$ \\
\hline Single & $76(4 \mid .3)$ \\
\hline Divorced & $3(1.6)$ \\
\hline \multicolumn{2}{|l|}{ Religion } \\
\hline Buddhist & $20(10.9)$ \\
\hline Christian & $8(4.3)$ \\
\hline Atheist & $148(80.4)$ \\
\hline Others & $7(3.8)$ \\
\hline \multicolumn{2}{|l|}{ Years of working experience } \\
\hline$<5$ & $73(39.7)$ \\
\hline $6-10$ & $49(26.6)$ \\
\hline $11-15$ & $34(18.5)$ \\
\hline $16-20$ & $21(11.4)$ \\
\hline$>21$ & $7(3.8)$ \\
\hline \multicolumn{2}{|l|}{ Department } \\
\hline Surgical oncology & $30(16.3)$ \\
\hline Medical oncology & $78(42.4)$ \\
\hline Radiation oncology & $20(10.9)$ \\
\hline Hematology oncology & $55(29.9)$ \\
\hline \multicolumn{2}{|l|}{ Education level } \\
\hline Technical secondary school graduates & $4(2.2)$ \\
\hline Junior colleague graduates & $45(24.5)$ \\
\hline Bachelor's & $130(70.7)$ \\
\hline Master's or above & $4(2.2)$ \\
\hline \multicolumn{2}{|l|}{ Posts } \\
\hline Clinical nurse & $136(73.9)$ \\
\hline Group leader & $35(19.0)$ \\
\hline Managers of head nurse or above & $13(7.1)$ \\
\hline \multicolumn{2}{|l|}{ Titles } \\
\hline Nurse & $48(26.1)$ \\
\hline Senior nurse & $99(53.8)$ \\
\hline Supervisor nurse & $35(19.0)$ \\
\hline Co-chief nurse or above & $2(I . I)$ \\
\hline
\end{tabular}


Table S2 PEAS tool

\begin{tabular}{|c|c|c|c|}
\hline \multirow[t]{2}{*}{ Part A: Questions } & \multicolumn{3}{|c|}{ Please put " $\sqrt{ }$ " in the appropriate box } \\
\hline & True & False & Not applicable \\
\hline \multicolumn{4}{|l|}{$\begin{array}{l}\text { I. In nursing school, I had studied about the care of patients with terminal } \\
\text { prognoses }\end{array}$} \\
\hline \multicolumn{4}{|l|}{$\begin{array}{l}\text { 2. In my nursing school clinical I had training in the care of patients } \\
\text { with terminal prognoses }\end{array}$} \\
\hline \multicolumn{4}{|l|}{ 3. I have made home hospice visits } \\
\hline \multicolumn{4}{|l|}{ 4. I have made inpatient hospice visits } \\
\hline \multicolumn{4}{|l|}{ 5. Someone close to me has died } \\
\hline \multicolumn{4}{|l|}{ 6. Someone close to me has had hospice services } \\
\hline \multicolumn{4}{|l|}{ 7. I have an advance directive (living will) for myself } \\
\hline \multicolumn{4}{|l|}{$\begin{array}{l}\text { 8. I have a durable power of attorney for health care decision making } \\
\text { for myself }\end{array}$} \\
\hline $\begin{array}{l}\text { 9. For each of the following questions, circle the most appropriate } \\
\text { response }\end{array}$ & & & \\
\hline
\end{tabular}

\section{Part B: Questions}

I. I would prefer to care for patients for whom I can do something, rather than patients with terminal prognosis

2. It is appropriate for colleagues to console one another when a patient dies

3. I feel angry when a patient of mine dies

4. I feel guilty when a patient of mine dies

5. Establishing rapport with a patient with a terminal prognosis is difficult for me

6. I wish I had more time to spend with my dying patients

7. It is hard for me to discuss advance directives when a patient is stable

8. It is inappropriate to discuss advance directives when a patient is stable

9. It is hard to know what to say when I have to talk with a patient about a terminal prognosis

I0. I value spending some of my free time with terminally ill patients and their families

II. I am acting unprofessionally if I cry in front of a dying patient or his/her family

12. I would be behaving unprofessionally if I were to become emotionally involved with my terminally ill patients

13. I am afraid I will get hurt if I get to know my terminally ill patients

14. I feel comfortable discussing end-of-life decisions with patients

15. Hiding my emotions makes it easier for me to talk to terminally ill patients

16. I find it easy to listen to patients with terminal prognoses talk about themselves

17. Being with a terminally ill patient is a waste of time

18. I avoid talking to dying patients

19. A patient with a terminal illness should be resuscitated over their stated objections in the event of a potentially fatal iatrogenic problem

20. If I were dying, I would want my physician to respect my wishes regarding end-of-life decision

2I. I feel comfortable helping bereaved families survive their loss

22. When I listen to a patient with a terminal illness, I am performing a beneficial therapeutic intervention

\begin{tabular}{|c|c|c|c|c|c|}
\hline \multicolumn{6}{|c|}{ Please put " $\sqrt{ }$ " on the appropriate number } \\
\hline $\begin{array}{l}\text { Not } \\
\text { applicable }\end{array}$ & $\begin{array}{l}\text { Strongly } \\
\text { disagree }\end{array}$ & Disagree & Neutral & Agree & $\begin{array}{l}\text { Strongly } \\
\text { agree }\end{array}$ \\
\hline 0 & I & 2 & 3 & 4 & 5 \\
\hline 0 & I & 2 & 3 & 4 & 5 \\
\hline 0 & 1 & 2 & 3 & 4 & 5 \\
\hline 0 & $\mathrm{I}$ & 2 & 3 & 4 & 5 \\
\hline 0 & I & 2 & 3 & 4 & 5 \\
\hline 0 & I & 2 & 3 & 4 & 5 \\
\hline 0 & I & 2 & 3 & 4 & 5 \\
\hline 0 & 1 & 2 & 3 & 4 & 5 \\
\hline 0 & I & 2 & 3 & 4 & 5 \\
\hline 0 & I & 2 & 3 & 4 & 5 \\
\hline 0 & I & 2 & 3 & 4 & 5 \\
\hline 0 & I & 2 & 3 & 4 & 5 \\
\hline 0 & I & 2 & 3 & 4 & 5 \\
\hline 0 & I & 2 & 3 & 4 & 5 \\
\hline 0 & I & 2 & 3 & 4 & 5 \\
\hline 0 & I & 2 & 3 & 4 & 5 \\
\hline 0 & I & 2 & 3 & 4 & 5 \\
\hline 0 & I & 2 & 3 & 4 & 5 \\
\hline 0 & I & 2 & 3 & 4 & 5 \\
\hline 0 & I & 2 & 3 & 4 & 5 \\
\hline 0 & $\mathrm{I}$ & 2 & 3 & 4 & 5 \\
\hline 0 & I & 2 & 3 & 4 & 5 \\
\hline
\end{tabular}


Table S2 (Continued)

\begin{tabular}{|c|c|c|c|c|c|c|}
\hline \multirow[t]{2}{*}{ Part B: Questions } & \multicolumn{6}{|c|}{ Please put "ل`" on the appropriate number } \\
\hline & $\begin{array}{l}\text { Not } \\
\text { applicable }\end{array}$ & $\begin{array}{l}\text { Strongly } \\
\text { disagree }\end{array}$ & Disagree & Neutral & Agree & $\begin{array}{l}\text { Strongly } \\
\text { agree }\end{array}$ \\
\hline $\begin{array}{l}\text { 23. I do not hug patients or their families because I am not that } \\
\text { kind of a person }\end{array}$ & 0 & 1 & 2 & 3 & 4 & 5 \\
\hline $\begin{array}{l}\text { 24. When I hug my patients and their families, I am providing } \\
\text { a therapeutic intervention }\end{array}$ & 0 & I & 2 & 3 & 4 & 5 \\
\hline $\begin{array}{l}\text { 25. It is my role as a nurse to address all sources of suffering with } \\
\text { the patient, whether they are existential, spiritual, emotional, } \\
\text { psychosocial or physical }\end{array}$ & 0 & 1 & 2 & 3 & 4 & 5 \\
\hline $\begin{array}{l}\text { 26. Allowing a terminally ill patient to die of an easily curable } \\
\text { problem such as pneumonia or sepsis is tantamount } \\
\text { to assisted suicide }\end{array}$ & 0 & I & 2 & 3 & 4 & 5 \\
\hline $\begin{array}{l}\text { 27. I feel as comfortable with a dying patient as I do with } \\
\text { any other patient }\end{array}$ & 0 & $\mathrm{I}$ & 2 & 3 & 4 & 5 \\
\hline $\begin{array}{l}\text { 28. Treating a dying patient is one of the most unpleasant aspects } \\
\text { of my profession }\end{array}$ & 0 & $\mathrm{I}$ & 2 & 3 & 4 & 5 \\
\hline $\begin{array}{l}\text { 29. Whenever possible, I avoid a person who is dying from } \\
\text { an irreversible condition }\end{array}$ & 0 & 1 & 2 & 3 & 4 & 5 \\
\hline 30. I try to avoid telling a patient directly that he/she is dying & 0 & $\mathrm{I}$ & 2 & 3 & 4 & 5 \\
\hline $\begin{array}{l}\text { 31. I find it more difficult to deal with the family of a dying } \\
\text { patient than with families of my other patients }\end{array}$ & 0 & I & 2 & 3 & 4 & 5 \\
\hline
\end{tabular}

Abbreviation: PEAS, Professional End-of-life Care Attitude Scale.

\section{Publish your work in this journal}

Patient Preference and Adherence is an international, peer-reviewed, open access journal that focuses on the growing importance of patient preference and adherence throughout the therapeutic continuum. Patient satisfaction, acceptability, quality of life, compliance, persistence and their role in developing new therapeutic modalities and compounds to optimize clinical outcomes for existing disease states are major areas of interest for the journal. This journal has been accepted for indexing on PubMed Central. The manuscript management system is completely online and includes a very quick and fair peer-review system, which is all easy to use. Visit http://www dovepress.com/testimonials.php to read real quotes from published authors. 